\title{
IMPACT OF QUALITY DECISIONS ON INFORMATION SHARING WITH SUPPLIER ENCROACHMENT
}

\author{
Rui Hou ${ }^{1}$, Weijian Li $^{1}$, Xiaogang Lin ${ }^{1}$ and You ZhaO ${ }^{1, *}$
}

\begin{abstract}
This study examines a retailer's decision to share market demand information in a supply chain wherein a supplier sells a product with a certain level of quality to a retailer, who then resells it to the end consumer. It also considers whether a supplier should establish a direct selling channel by incurring a fixed entry cost to compete with the retail channel. Although conventional wisdom indicates that a retailer may voluntarily disclose information under ex-ante supplier encroachment, our results show how and why a retailer may share information with the supplier who encroaches on the retail market with a decision on quality. Specifically, our findings reveal that information sharing is beneficial to the retailer when the quality cost coefficient is low and entry cost is relatively low, even under encroachment by the supplier. Moreover, the retailer may prefer to disclose demand information to the supplier if the quality cost coefficient is low, even when the entry cost is high, under non-encroachment. Interestingly, we found that the supplier prefers to encroach if the retailer shares demand information when the entry cost is moderate. Further, we found that the retailer has a higher incentive to share information under supplier encroachment compared with non-encroachment. These results are in sharp contrast with the extant literature.
\end{abstract}

Mathematics Subject Classification. 91A12, 91A40, 91B24, 90B60.

Received January 5, 2021. Accepted December 16, 2021.

\section{INTRODUCTION}

Suppliers who are involved in direct sales over the Internet (e.g., IBM, Pioneer Electronics, Cisco Systems, Estee Lauder, and Nike) generally seem to lead to "channel conflict" [5]. Intuitively, this is detrimental for the retailer who is encroached upon because some consumers are inclined to purchase from a direct channel. For example, Procter \& Gamble, the second largest fast-moving consumer goods company globally, sells products solely via retail outlets such as supermarkets and convenience stores ${ }^{1}$. However, when other suppliers convince retailers to use a direct channel, it may result in a win-win situation for both firms, as they tap into segments of consumers who would not buy otherwise $[5]^{2}$. This activity-suppliers setting up their own channels to sell

Keywords. Game theory, information sharing, quality decision, supplier encroachment.

1 School of Management, Guangdong University of Technology, Guangzhou, Guangdong510520, P.R. China.

*Corresponding author: zhaoyou728@outlook.com

${ }^{1}$ See https://www. consultancy.uk/news/26874/the-worlds-40-largest-fast-moving-consumer-goods-companies

${ }^{2}$ For example, Herman Miller Inc., an office furniture manufacturer in Zeeland, Michigan, carefully explained to its dealers that its online efforts are aimed at the home office market, a segment that its dealer network was not serving.

(c) The authors. Published by EDP Sciences, ROADEF, SMAI 2022 
products directly to send consumers over using traditional retail channel-could be defined as supplier encroachment. This practice has been hugely promoted in the e-commerce economy.

Nevertheless, it may be costly for suppliers to establish their own channels. Doing so would involve expenses such as enrollment, website development and maintenance, and company-owned franchises [38]. As such, the lucrativeness of encroachment depends on the cost (i.e., entry cost) and market demand information of the end consumer. When suppliers lack this information, they would most likely not encroach as they are likely to find it difficult to accurately weigh the surplus between the potential value and entry cost. However, supply chain partners might be able to address this issue of demand information asymmetry among upstream and downstream firms. This is because the retailer's decision to share demand information could be beneficial to both firms despite the supplier's encroachment $[1,6]$.

Although demand information is an important factor supporting the decision of encroachment, product quality may also be considered. According to [3], upstream firms often sell products via different channels. In the automobile industry, manufacturers sell products of varying qualities depending on the market demand and distribution system [42]. Similarly, in the wine industry, manufacturers may distribute wines of varying and diverse qualities via their channel structure [12]. In the cosmetics industry, in which quality differences are more apparent, manufacturers may choose to provide products with lower densities to markets abroad. However, examples of encroachment exist in most of the aforementioned industries. Given the prevalence of a combination structure that includes information sharing, upstream encroachment, and quality decisions in the marketplace, the impact of quality decisions on the retailer's information sharing with supplier encroachment is unclear. To fill this gap, the following questions need to be examined:

- How do retailers adjust their information sharing policy with the supplier, who makes decisions on encroachment and product quality?

- How do suppliers make decisions on encroachment and product quality in response to information sharing in the supply chain?

To answer these questions, we employed a standard-form information sharing model, in which the supply chain comprises a supplier (he) who sells a product with a certain quality level to a retailer (she), and the product quality cost is viewed as having a quadratic function form. The supplier, however, could also establish a direct selling channel to compete with the retail channel, thus incurring a simultaneous fixed entry cost. Accordingly, four scenarios are considered in this study: (i) "NN": the retailer does not share information, nor does the supplier encroach; (ii) "NE": the retailer shares no information with the supplier, who chooses to encroach on the retail channel; (iii) "SN": the retailer decides to share information with the supplier, who does not encroach; and (iv) "SE": the retailer shares information while the supplier adopts an encroachment policy.

Importantly, the retailer, who is closer to the end consumer, can better observe the market demand signal, whereas the supplier only has a prior belief about it because of his remoteness from consumers [13]. The timeline of the game is as follows. First, the retailer decides whether to share demand information with the supplier. Second, the supplier determines whether to establish a direct selling channel after observing the retailer's decision to share information. Third, the retailer observes the demand signal during the selling season. Finally, both firms determine retail quantities and engage in Cournot competition. Note that if the supplier decides not to encroach, the retailer only sets the retail quantity.

Our major contributions are summarized as follows. First, in our basic model analysis, the retailer may, surprisingly, share demand information with her supplier voluntarily. If the supplier does not encroach, then information sharing is beneficial to the retailer when the quality cost coefficient is low. Further, if the supplier encroaches, the retailer prefers to share demand information with the supplier when the quality cost coefficient is moderate. Interestingly, we find that the supplier prefers to encroach if the retailer shares demand information when the entry cost is moderate. Note that the threshold of the quality cost coefficient depends on channel substitutability, that is, under a product quality decision, the retailer always has an incentive to share demand information with the supplier regardless of encroachment. These results are in sharp contrast with 
[13], who showed that the retailer may not share demand information with the supplier because of the double marginalization effect of information sharing.

Second, the retailer has more incentive to share demand information under supplier encroachment compared with non-encroachment. This is because the supplier can adjust the product quality based on his prior beliefs or the retailer's shared information, which further improves market demand. As such, the retailer is more willing to share information in response to the supplier's efforts so that a win-win situation can be achieved. Moreover, we introduce some extensions in our model, such as the sequential quantity decision, pricing competition, and supplier encroachment timing, to confirm the robustness of our obtained results.

Third, we show that the supplier prefers to establish a direct selling channel when the quality cost coefficient is high. Specifically, when the threshold of entry cost increases with the quality cost coefficient, it is more profitable for the supplier to encroach on the retail channel. Our findings shed light on problems occurring because of the impact of quality-related decisions on retailers' information sharing when a supplier encroaches in the marketplace.

The remainder of this paper is organized as follows. We review the literature in Section 2. Section 3 introduces our basic model. Next, we analyze the retailer's equilibrium information sharing decision and the supplier's encroachment decision in Section 4. We then discuss some extensions of our basic model in Section 5. Finally, Section 6 concludes our paper and examines the scope for future research. All proofs are presented in the Appendix.

\section{Literature REVIEW}

Our research builds upon previous works on the information sharing problem, product quality decisions, and encroachment decisions. In the following, we briefly review the research most relevant to our study.

Extant studies focused on the impact of information sharing [see, e.g., 15, 16, 19, 21, 32, 33, 40]. [9] showed that the retailer would not share demand information with her supplier because of the double marginalization effect of information sharing. [11] considered the information sharing problem with two competing supply chains, in which the manufacturer determines the cost reduction level. They show that information sharing is beneficial to the supply chain wherein the manufacturer can buy information from the retailer. [13] studied a retailer's incentive to share information while under supplier encroachment. The retailer voluntarily shares demand information with her supplier to deter the supplier's encroachment. Based on this result, [46] focused on an e-tailer's information sharing decision problem with supplier encroachment, wherein the e-tailer sells a product by agency selling or reselling. They found that the e-tailer prefers to share demand information under agency selling, whereas he or she withholds it under reselling, in which the supplier incurs a small or large entry cost. [22] studied the information sharing problem in a supply chain with a manufacturer and multiple retailers. They found that if retailers disclosed information confidentially, the supply chain can gain the most profits. However, if there is no confidentiality, then information sharing becomes unfeasible. Further, [28] investigated the retail platform's information sharing decision problem with multiple sellers, that is, whether the platform should share demand information with its sellers. They show that the retail platform and sellers can benefit from information sharing, that is, achieve a "win-win" situation. However, the above studies considered only the demand information sharing problem, while [7] considered quality information sharing with supplier encroachment. When the supplier encroaches, that supplier's ex-ante payoffs decrease and he may decide not to encroach. Again, [8] considered a two-period quality disclosure problem with online reviews. They showed that the seller will charge a higher selling price in the first period when the seller withholds low information in advance. [48] considered a supply chain consisting of an e-tailer who may share demand information with the supplier under agency selling and reselling. By comparing the manufacturer-quantity-leader game and the retailer-quantity-leader game, [43] examined the conditions of spillover intensity and demand information value to occupy the quantity decision leadership.

Apart from information sharing, product quality decisions are also an important issue in supply chain management [see, e.g., 2, 20,30,44]. [42] investigated a pricing and quality decision problem in a supply chain with 
a manufacturer and a retailer, and they determined the manufacturer's product quality level by judging the properties of the marginal revenue function. [18] developed a dynamic model to study the impact of a firm's pricing and quality decisions on goods. They showed that the firm may decrease product quality instead of increasing it when the efficiency is high. [23] studied a product's pricing and quality decisions when considering demand risk. They found that a risk-averse firm prefers to determine a lower price and quality when the price and quality are set. [39] studied a case in which a manufacturer sells high- and low-quality products through a direct selling channel and a retailer's reselling channel. The results revealed that the manufacturer's product distribution strategy relies on the type of product.

Our work also relates to suppliers' encroachment in a supply chain [see, e.g., 4, 24, 25, 27, 29]. [1] showed that encroachment is beneficial to the retailer when no synergies are admitted by the supplier. This is because encroaching firms prefer to decrease wholesale prices when competition between the two channels is increased, thereby mitigating double marginalization. Based on this, [24] studied a supplier encroachment problem in which the retailer may be better than a supplier who is informed. They found that the retail quantity is reduced when the market size is small, because the retailer then faces high costs incurred by the establishment of the supplier's channel, resulting in worse double marginalization. [10] investigated a one-to-one supply chain with supplier encroachment, in which the product quality is set as endogenous. They demonstrated that the retailer always benefits from supplier encroachment. Further, the supplier prefers to sell the high-quality product through his own channel when quality differentiated products are offered. Following this, [47] investigated the supplier encroachment problem with an endogenous product quality decision under asymmetric information. They found that when the entry cost is intermediate, encroachment results in a lower quality product. Moreover, the retailer prefers to share information with its supplier to reduce risk when the supplier is efficient. [6] developed a dynamic model to study the interaction between strategical inventory and supplier encroachment in the second period. They showed that the retailer prefers to withhold inventory in certain cases, which results in the supplier encroaching less aggressively. Additionally, the retailer may gain more profits in the simultaneous case, compared with the sequential case, in certain scenarios. [36] showed that, under either the asymmetric or symmetric demand information, encroachment may motivate the manufacturer to invest more in cost reduction, which may be beneficial to both firms. In a retailer-led supply chain, [48] demonstrated that the retailer may achieve anti-encroachment through retail service investing, which may lead to Pareto improvement. When deciding whether to encroach, [37] showed that with encroachment, a cost decline always hurts the retailer and benefits the supplier, only if the direct selling cost is not very high.

Unlike the above studies, to the best of our knowledge, we are the first to investigate the interaction between information sharing, quality decision, and supplier encroachment.

\section{THE MODEL}

We considered a supply chain with a supplier (he, denoted as subscript "S") and a retailer (she, denoted as subscript "R"). The supplier sells a product at wholesale price $w$ with quality level $m$ to the retailer and incurs a cost on the quality of effort, $\frac{1}{2} \mathrm{~km}^{2}$, where $k$ is the quality cost coefficient ${ }^{3}$. However, he can also choose to directly sell the product to consumers. Similar to [13], we assume that if the supplier decides to encroach, he also incurs an exogenous fixed entry cost of $F$. The market potential demand can be expressed as $a+\theta$, where $a$ is a sufficiently large constant number, and $\theta$ measures market demand uncertainty, which follows a normal distribution with zero mean and variance $\sigma^{2}$. As demonstrated in the literature [11,13,22,24,31,34], the retailer could accurately and precisely infer the true value of $\theta$ from her extensive data, whereas the supplier can only infer the distribution information of market uncertainty. Note that the aforementioned assumption would not change our main results. Therefore, we also consider that the retailer has a perfect forecast of $\theta$; this simplifies the notation and derivations of our analytical results, which is reasonable. Importantly, we assume that the retailer acts as a Stackelberg leader and decides whether to share demand information with the supplier. Then, the supplier determines whether to encroach after the information decision is provided.

\footnotetext{
${ }^{3}$ This quadratic cost function form is widely adopted in supply chain management literature [see, e.g., 11, 26].
} 
TABLE 1. Notation.

\begin{tabular}{ll}
\hline \hline Notations & Explanation \\
\hline$a$ & base market demand \\
$\theta$ & random maket demand $\theta \sim N\left(0, \sigma^{2}\right)$ \\
$m$ & product quality level \\
$b$ & channel substitutability \\
$k$ & cost of the product quality \\
$F$ & supplier's fixed entry cost \\
$p_{r}\left(p_{s}\right)$ & the price in direct channel (reselling channel) \\
$q_{r}\left(q_{s}\right)$ & the quantity in direct channel (reselling channel) \\
$w$ & wholesale price \\
$\pi_{s}$ & profit of the supplier \\
$\pi_{r}$ & profit of the retailer \\
\hline
\end{tabular}

The utility function for a representative consumer is given by

$$
U\left(q_{r}, q_{s}\right)=(a+\theta+m)\left(q_{r}+q_{s}\right)-\frac{1}{2}\left(q_{r}^{2}+2 b q_{r} q_{s}+q_{s}^{2}\right)-\left(p_{r} q_{r}+p_{s} q_{s}\right),
$$

which is widely adopted by $[1,13,35]$. Consequently, if the supplier determines not to encroach, let subscript "r" denote the retailer's channel. Then, the inverse demand function is given by $p_{r}\left(q_{r}\right)=a+\theta+m-q_{r}$, where $q_{r}$ is the retail quantity set by the retailer [this inverse demand function is widely adopted in the information sharing literature; see, e.g., 7,8,11,13]. Conversely, if the supplier decides to encroach, there exists a quantity (Cournot) competition between the retailer and supplier. However, we also study a price (Bertrand) competition between the downstream and upstream firms in Section 4. Let subscript "s" denote the direct channel by solving the first-order conditions of equation (3.1). Also, we assume that two channels are symmetric and interchangeable in that consumers could perceive the two channels to be partial substitutability. Thereby, the inverse demand functions are respectively given by

$$
\begin{aligned}
& p_{r}\left(q_{r}, q_{s}\right)=a+\theta+m-q_{r}-b q_{s}, \\
& p_{s}\left(q_{r}, q_{s}\right)=a+\theta+m-q_{s}-b q_{r},
\end{aligned}
$$

where $q_{i}, i \in\{r, s\}$ shows the retail quantity from firm $i$, and $b, 0<b \leq 1$, represents the channel substitutability or competition intensity ${ }^{4}$. Moreover, we assume that the production cost of the supplier, the selling cost, and the service cost are normalized to zero. According to this, supply chain members make the pricing (quantity) decisions ${ }^{5}$. Table 1 lists the notations used in this study with their explanations.

Decision sequence. The timeline of the game is shown in Figure 1. The retailer first determines whether to share demand information with her supplier, a setting that is widely adopted by $[14,41,46]$. Next, the supplier decides whether to encroach after the information decision is provided. Then, the information is acquired. Notably, this setting is in line with practice because accurate market information can only be obtained near the beginning of the sales season. Next, the supplier sets product quality $m$ and determines wholesale price $w$ for the retailer. Finally, the retailer and supplier simultaneously decide on retail quantity $q_{r}$ in the reselling channel and $q_{s}$ in the direct selling channel (if he encroaches) or retail quantity $q_{r}$ in the reselling channel (if he

\footnotetext{
${ }^{4}$ The representative consumer of the same type maximizes $U\left(q_{r}, q_{s}\right)$ to obtain the inverse demand functions. It is worth noting that when $b=0$, the inverse demand is independent from each other, and when $b \rightarrow 1$, the competition between the two firms is fierce.

${ }^{5}$ We thank an anonymous reviewer for pointing out that the market potential should be changed when the supplier encroaches. Note that it is difficult to incorporate this setting in the encroachment research when supply chain members did not make any effort to expand the market potential (e.g., through advertising).
} 


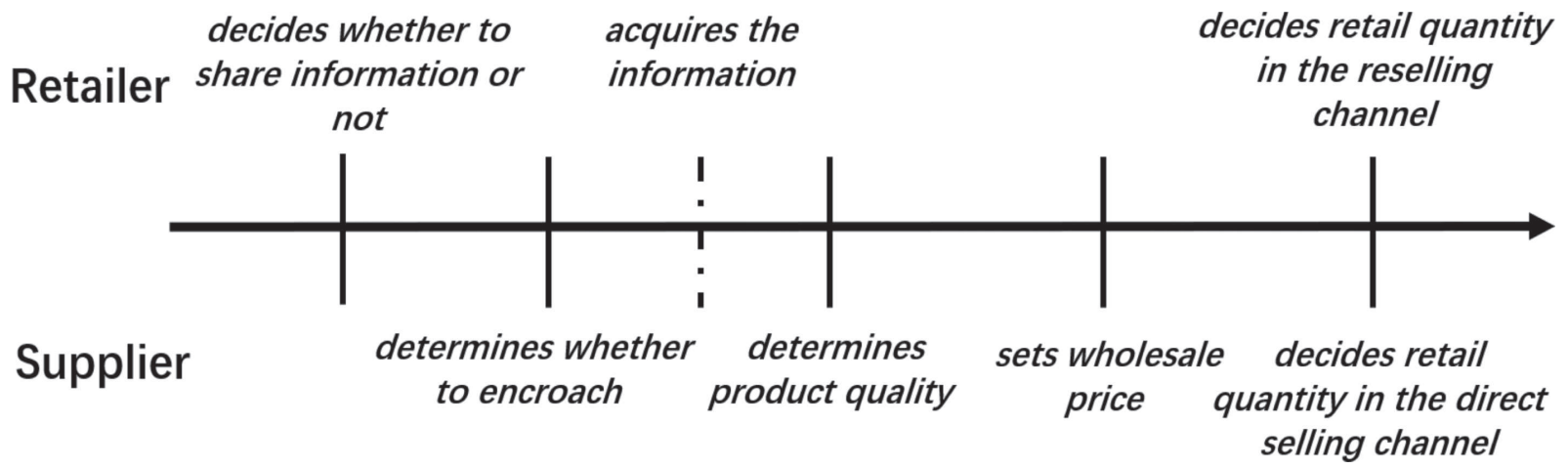

Figure 1. Timeline of the game.

decides not to encroach). Thus, arguably, the retailer and supplier determine retail quantities simultaneously. This assumption is reasonable, because if the retailer decides the retail quantity before the supplier, the quality level, wholesale price, and retail quantity are functions of $a$ and $\theta$. Subsequently, the supplier can infer market demand information.

However, we also consider a case in which the supplier decides the wholesale price and retail quantity simultaneously before the retailer sets her retail quantity in Section 4. We investigate the interaction between the supplier's encroachment, retailer's information sharing, and quality decision. According to [24,40,45], when the supplier encroaches the retail channel and thus directly sells products to consumers, the retailer must determine her selling quantity after encroachment. Otherwise, the supplier could infer the demand information, which will be discussed in Section 5.1.

We solve this game backwards. First, the retailer's information decision and supplier's encroachment decision are provided. Next, the retail quantities are solved for both the retailer and the supplier. Afterwards, we obtain the equilibrium outcomes and compare them under different scenarios.

In the next section, we examine the retailer's information decision and supplier's encroachment decision.

\section{EQUILIBRIUM ANALYSIS}

In this section, when the retailer's information sharing decision is determined, we first investigate the supplier's encroachment decision. Next, we show the conditions of the retailer's information decision by comparing ex-ante profits between the non-information-sharing and information-sharing scenarios.

\subsection{Encroachment decisions}

Non-information-sharing. Let superscript "NN" denote this case, wherein the retailer would not share demand information and the supplier also does not encroach on the retail channel. We first solve the maximization problem $\max _{q_{r}} \pi_{r}=\left(a+\theta+m-q_{r}-w\right) q_{r}$ to obtain the optimal quantity $q_{r}^{N N}=\frac{a+\theta+m-w}{2}$. Next, the supplier obtains the optimal wholesale price by solving $\max _{w} \pi_{s}=E\left[\left(a+\theta+m-q_{r}^{N N}-w\right)\right] w-\frac{k m^{2}}{2}$; thereby, the optimal wholesale price is $w^{N N}=\frac{a+m}{2}$. Finally, the optimal product quality level $m^{N N}=\frac{a}{4 k-1}$ is obtained by solving $\max _{m} \pi_{s}=E\left[\left(a+\theta+m-q_{r}^{N N}-w^{N N}\right)\right] w^{N N}-\frac{k m^{2}}{2}$. However, we assume $k>\frac{1}{4}$ to ensure the equilibrium is solved positively.

If the supplier decides to encroach, the supply chain has a direct selling channel and a reselling channel, and the retailer has market demand information. Let superscript "NE" denote this case. The supplier's and retailer's 
profit functions are respectively given by

$$
\begin{aligned}
& \pi_{s}=E\left[\left(a+\theta+m-q_{r}-b q_{s}\right) q_{s}+w q_{r}-\frac{k m^{2}}{2}-F\right], \\
& \pi_{r}=\left(a+\theta+m-q_{s}-b q_{r}-w\right) q_{r} .
\end{aligned}
$$

According to the first-order optimality condition, we can first obtain the retailer's optimal order quantity $q_{r}=\frac{1}{2}\left(a+\theta+m-w-b q_{s}\right)$. Similarly, the supplier's optimal quantity is given by $q_{s}=\frac{1}{2}\left(a+m-b E\left[q_{r}\right]\right)$. By solving these two equations jointly, we can have $q_{r}^{N E}=\frac{a(2 b-4)+(2 b-4) m+\left(b^{2}-4\right) \theta-4 w}{2\left(4-b^{2}\right)}$ and $q_{s}^{N E}=\frac{a(b-2)+(b-2) m-b w}{4-b^{2}}$. Then, the supplier maximizes his expected profit to obtain the optimal wholesale price $w^{N E}=-\frac{\left[8+(b-4) b^{2}\right](a+m)}{6 b^{2}-16}$. Finally, the optimal quality is given by $m^{N E}=-\frac{a(b-2)(b-6)}{12-16 k+b(-8+b+6 b k)}$. However, we assume that $k>\frac{8 b-b^{2}-12}{6 b^{2}-16}>\frac{1}{4}$ to ensure the equilibrium is solved positively.

Based on the above description, we are now ready to answer the question of whether the supplier should encroach when the retailer decides on a non-information sharing policy. For convenience, we define the following function to represent the expected profit gap between cases "NN" and "NE," denoted as "N":

$$
\Gamma_{N}=-\frac{[16+b(5 b-16)] k^{2} a^{2}}{(4 k-1)[12-16 k+b(-8+b+6 b k)]} .
$$

Further, we define the supplier's encroachment decision, as in the following lemma.

Lemma 4.1. If the retailer withholds demand information, the supplier would want to encroach if and only if $F \leq \Gamma_{N}$, where $\frac{\partial \Gamma_{N}}{\partial b}<0$ and $\frac{\partial \Gamma_{N}}{\partial k}>0$.

Some observations can be obtained from Lemma 4.1. The supplier encroaches when the entry cost is lower than or equal to the threshold $\Gamma_{N}$, because he will obtain more revenue this way. Moreover, we find that a higher $b$ will lead to a lower threshold $\Gamma_{N}$; that is, the supplier is hurt by the fierce competition between the direct selling channel and the reselling channel. Interestingly, the supplier can gain more profits from encroachment when the quality cost coefficient $k$ increases.

Information sharing. Let superscript "SN" denote the case wherein the retailer shares her private demand information and the supplier cannot encroach. Given optimal quantity $q_{r}^{S N}=\frac{a+\theta+m-w}{2}$, the supplier obtains the optimal wholesale price by solving $\max _{w} \pi_{s}=\left(a+\theta+m-q_{r}^{S N}-w\right) w-\frac{k m^{2}}{2}$; thereby, the optimal wholesale price can be expressed as $w^{S N}=\frac{a+\theta+m}{2}$. Finally, the optimal product quality level is given by $m^{S N}=\frac{a+\theta}{4 k-1}$.

Consider if the supplier chooses to encroach when the retailer discloses demand information, denoted as "SE." Similarly, consider if $q_{r}^{S E}=\frac{a(b-2)+(b-2) m+(b-2) \theta-b w}{4-b^{2}}$ and $q_{s}^{S E}=\frac{a(b-2)+(b-2) m+(b-2) \theta-b w}{4-b^{2}}$. Accordingly, we can easily have $w^{S E}=\frac{\left[8+(b-4) b^{2}\right](a+m+\theta)}{16-6 b^{2}}$ and $m^{S E}=-\frac{(a+\theta)(b-2)(b-6)}{12-16 k+b(-8+b+6 b k)}$. We are now ready to determine whether the supplier should encroach if the retailer shares demand information by comparing the expected profit between cases "SN" and "SE," as shown in the following function, denoted as "S":

$$
\Gamma_{S}=-\frac{[16+b(5 b-16)] k^{2}\left(a^{2}+\sigma^{2}\right)}{(4 k-1)[12-16 k+b(-8+b+6 b k)]} .
$$

Further, we determine the supplier's encroachment decision, as in the following proposition.

Lemma 4.2. If the retailer's demand information is shared with the supplier, the supplier chooses to encroach if and only if $F \leq \Gamma_{S}$, where $\frac{\partial \Gamma_{S}}{\partial b}<0, \frac{\partial \Gamma_{S}}{\partial k}>0$, and $\frac{\partial \Gamma_{S}}{\partial \sigma^{2}}>0$.

Lemma 4.2 suggests that the supplier's encroachment decision relies on channel substitutability, variance of the market demand, and quality cost coefficient when he is informed. Unlike Lemma 4.1, when threshold $\Gamma_{S}$ includes $\sigma^{2}$, a higher $\sigma^{2}$ results in the supplier gaining more benefits, meaning that he prefers to encroach. 
Proposition 4.3. If $\Gamma_{N}<F \leq \Gamma_{S}$ and $\frac{8 b-b^{2}-12}{6 b^{2}-16}<k \leq k_{0}$, the supplier encroaches under the information sharing condition but not under the non-information sharing condition.

Based on Proposition 4.3, we obtain an interesting result when the supplier's encroachment cost lies in an interval; that is, $F_{N}<F \leq F_{S}$, in which the supplier's encroachment decision depends on the retailer's information sharing policy. Concretely, if the retailer shares the information, the supplier prefers to encroach; otherwise, he has no incentive to encroach. Accordingly, the retailer is inclined to share information when $\frac{8 b-b^{2}-12}{6 b^{2}-16}<k \leq k_{0}$, that is, when $\pi_{r}^{S E}>\pi_{r}^{N N}$ holds. We now examine whether the retailer should disclose demand information to the supplier voluntarily.

\subsection{Information sharing decisions}

Based on the previous encroachment decision, we now examine the information sharing decision. When the retailer rejects the sharing of demand information, her ex-ante profits are dependent on the supplier's encroachment decision:

$$
\pi_{r}^{N}= \begin{cases}\frac{[8 a(b-1) k]^{2}+[12-16 k+b(-8+b+6 b k)]^{2} \sigma^{2}}{4(12-16 k+b(-8+b+6 b k)]^{2}} & \text { if } F \leq \Gamma_{N}, \text { encroachment } \\ \frac{4 k^{2}\left(a^{2}+4 \sigma^{2}\right)+(1-8 k) \sigma^{2}}{4(1-4 k)^{2}} & \text { if } F>\Gamma_{N}, \text { no encroachment. }\end{cases}
$$

When the retailer shares demand information, her ex-ante profits are given by

$$
\pi_{r}^{S}= \begin{cases}\frac{16(b-1)^{2} k^{2}\left(a^{2}+\sigma^{2}\right)}{[12-16 k+b(-8+b+6 b k)]^{2}} & \text { if } F \leq \Gamma_{S}, \text { encroachment } \\ \frac{k^{2}\left(a^{2}+\sigma^{2}\right)}{(1-4 k)^{2}} & \text { if } F>\Gamma_{S}, \text { no encroachment. }\end{cases}
$$

According to equations (4.5) and (4.6), we are now ready to answer the question of whether the retailer should share demand information with her supplier, as stated in the following proposition.

Theorem 4.4. In equilibrium, the retailer prefers to share demand information when one of the following conditions hold:

(i) if $F \leq \Gamma_{N}$ and $\frac{8 b-b^{2}-12}{6 b^{2}-16}<k \leq \frac{6-b}{4+6 b}$,

(ii) if $F>\Gamma_{S}$ and $\frac{1}{4}<k \leq \frac{1}{2}$.

Extant literature has shown that the downstream firm does not share demand information with the upstream firm owing to the double marginalization effect. Intuitively, the retailer withholds this information, which gives her an advantage. [13] suggested that the retailer has no incentive to share demand information with the manufacturer, as the deterrence effect disappears in this case of ex-ante encroachment. In other words, the retailer is unwilling to share her private demand observation when the supplier makes an encroachment decision. Surprisingly, by Theorem 4.4, we find that the retailer shares her private demand information voluntarily regardless of the encroachment decision made by the supplier. More specifically, information sharing is beneficial to the retailer if the quality cost coefficient is relatively low and when the entry cost is low under the supplier's encroachment. That is, the supplier may lead the retailer to share the information. Traditionally, if the supplier is informed, he will adjust a higher wholesale price, which worsens the double marginalization problem. However, the retailer prefers to share demand information when the quality cost coefficient is low because she benefits from adjusting the product quality level. Moreover, we show that when the intensity of channel competition increases, the value of $\frac{6-b}{4+6 b}$ decreases. That is, the retailer's incentive to share demand information worsens when competition intensifies. Intuitively, channel competition becomes intense when the supplier encroaches, and the retailer may therefore prefer to withhold demand information to deter the supplier's channel. However, the retailer may also prefer to disclose this information to the supplier if the quality cost coefficient is low and when the entry cost is high under non-encroachment.

Corollary 4.5. (i) For any $b \in(0,1]$, the following relationships always hold: $\frac{1}{4}<\frac{8 b-b^{2}-12}{6 b^{2}-16}$ and $\frac{1}{2}<\frac{6-b}{4+6 b}$. (ii) The retailer's and supply chain's equilibrium profits all monotonically increase with the quality cost coefficient, whereas the supplier's equilibrium profits decrease with it. 
Corollary 4.5(i) indicates that for any given value of channel substitutability, when the information is shared, both the upper and lower bounds of the interval of the quality cost coefficient under supplier encroachment are higher than those under non-encroachment. In other words, the retailer's incentive to share information under encroachment is higher than that under non-encroachment. This is because the supplier can gain profits from both the direct selling channel and reselling channel when he encroaches. Therefore, he prefers to improve product quality to enhance market demand. Thus, the retailer would also like to share demand information in response to the supplier.

Part(ii) suggests that the retailer and the whole supply chain can benefit from the supplier's efforts toward product quality, whereas the supplier is hurt by it.

Proposition 4.6. Under supplier encroachment, the equilibrium profits of the retailer, supplier, and supply chain all monotonically decrease with channel substitutability.

[13] suggests that the supply chain members' profits are all non-monotonic with $b$. This is because a higher $b$ may result in a decrease in the supplier's profits and also lead the retailer to share demand information. However, Proposition 4.6(i) indicates that when the supplier encroaches-that is, when there exists channel substitutability-as $b$ increases, the supply chain members' profits decrease, which is in line with [41].

\section{Discussion}

In our basic model, we study the interaction between the supplier's encroachment, the retailer's information sharing, and the quality decision. We present that the retailer may share her private demand information with the supplier voluntarily when the quality cost coefficient is relatively low and the entry cost is high, or if the quality cost coefficient and entry cost are low. However, one may be concerned about the robustness of our basic model. In the following, we discuss three directions to show that our results hold to our basic assumptions: (i) sequential quantity decision, (ii) price (Bertrand) competition, (iii) supplier encroachment timing.

\subsection{Sequential quantity decision}

As explained in Section 3, the supplier and retailer set retail quantities simultaneously when the information sharing decision and wholesale price are provided (see, e.g., [1]). In practice, other sequential quantity decisions are considered $([10,24])$. In this subsection, two alternative sequences for quantity are examined. A previous study [1] considered a situation in which the supplier could determine the quantity and wholesale price simultaneously before the retailer sets her retail quantity. Consequently, we first focus on the scenario in which the supplier determines the direct quantity before the retailer determines her selling quantity, referred to as Sequential (I); see Figure 2. Moreover, as we posited in Section 3, the retailer may first decide $q_{R}$ following which the supplier decides $q_{S}$, leading to a signal game in the supply chain, referred to as Sequential (II); see Figure 3. Therefore, we now study the impact of the sequential quantity decision on the retailer's information decision and supplier's encroachment decision. It is worth noting that if the supplier rejects encroachment, the equilibrium outcomes are the same as those in the basic model.

Sequential (I): Non-information sharing. According to the first-order optimality condition, we first obtain the retailer's optimal order quantity $q_{r}=\frac{1}{2}\left(a+\theta+m-w-b q_{s}\right)$. Afterwards, the supplier maximizes his expected profit to obtain the optimal wholesale price $w^{N E}=\frac{1}{2}(a+m)$ and optimal retail quantity $q_{s}^{N E}=\frac{a(b-2)+(b-2) m}{2\left(b^{2}-2\right)}$. Finally, the optimal quality $m^{N E}=\frac{a(2 b-3)}{3-2 b+2\left(b^{2}-2\right) k}$. However, we assume that $k>\frac{2 b-3}{2 b^{2}-4}>\frac{1}{4}$ to ensure the equilibrium is solved positively.

Based on the above description, we are now ready to answer the question of whether the supplier should encroach when the retailer refuses to share demand information with him. For convenience, we define the following function to represent the expected profit gap, denoted as superscript "B":

$$
\Gamma_{N}^{B}=-\frac{a^{2}(b-2)^{2} k^{2}}{4(1-4 k)\left(3-2 b+2\left(b^{2}-2\right) k\right)} .
$$




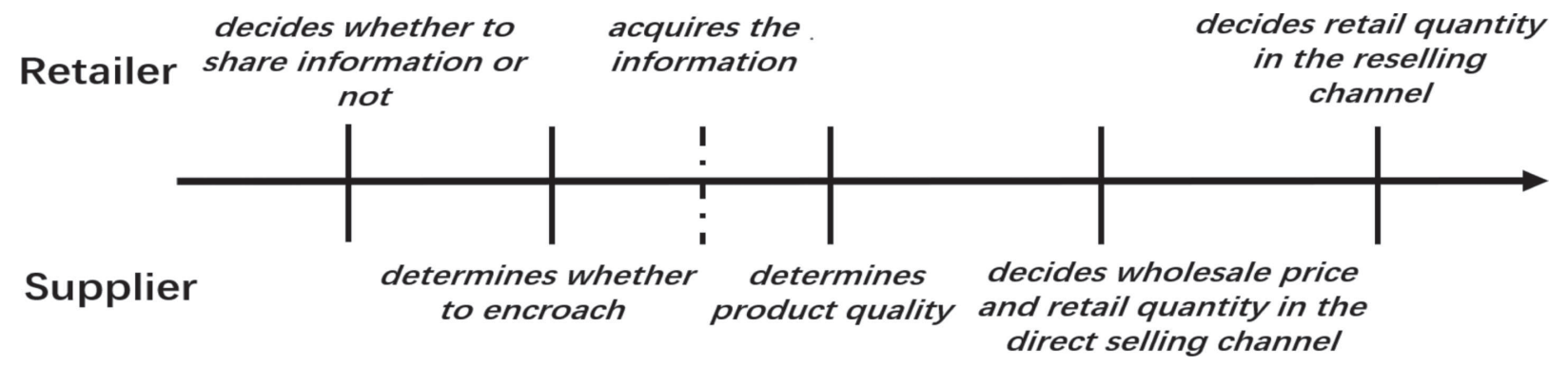

Figure 2. Game timing of sequential (I).

Information sharing. Similarly, given that $q_{r}^{S E}=\frac{1}{2}\left(a+\theta+m-w-b q_{s}\right)$, we can easily have $w^{S E}=\frac{1}{2}(a+m+\theta)$ and $q_{s}^{S E}=\frac{a(b-2)+(b-2) m+(b-2) \theta}{2\left(b^{2}-2\right)}$. Then, the optimal quality is given by $m^{S E}=\frac{(a+\theta)(2 b-3)}{3-2 b+2\left(b^{2}-2\right) k}$. We are now ready to answer the question of whether the supplier should encroach if the retailer shares demand information by comparing the expected profits:

$$
\Gamma_{S}^{B}=-\frac{(b-2)^{2} k^{2}(a+\theta)^{2}}{4(1-4 k)\left(3-2 b+2\left(b^{2}-2\right) k\right)} .
$$

Based on the previous supplier's encroachment decision, we study the retailer's information sharing decision. When the retailer does not share demand information, her ex-ante profits depend on the supplier's encroachment decision:

$$
\pi_{r}^{N}= \begin{cases}\frac{4 a^{2}(b-1)^{2} k^{2}+\left(3-2 b+2\left(b^{2}-2\right) k\right)^{2} \sigma^{2}}{4\left(3-2 b+2\left(b^{2}-2\right) k\right)} & \text { if } F \leq \Gamma_{N}^{B}, \text { encroachment } \\ \frac{4 k^{2}\left(a^{2}+4 \sigma^{2}\right)+(1-8 k) \sigma^{2}}{4(1-4 k)^{2}} & \text { if } F>\Gamma_{N}^{B}, \text { no encroachment. }\end{cases}
$$

When the retailer shares demand information, her ex-ante profits are given by

$$
\pi_{r}^{S}= \begin{cases}\frac{(b-1)^{2} k^{2}\left(a^{2}+\sigma^{2}\right)}{\left(3-2 b+2\left(b^{2}-2\right) k\right)^{2}} & \text { if } F \leq \Gamma_{S}^{B}, \text { encroachment, } \\ \frac{k^{2}\left(a^{2}+\sigma^{2}\right)}{(1-4 k)^{2}} & \text { if } F>\Gamma_{S}^{B}, \text { no encroachment. }\end{cases}
$$

According to equations (5.3) and (5.4), we now present the firms' equilibrium decisions, as stated in the following proposition.

Proposition 5.1. In equilibrium, the retailer prefers to share demand information when one of the following conditions hold:

(i) If $F \leq \Gamma_{N}^{B}$ and $\frac{2 b-3}{2 b^{2}-4}<k \leq \frac{2 b-3}{2 b^{2}-2 b-2}$, then the supplier always encroaches.

(ii) If $\Gamma_{N}^{B}<F \leq \Gamma_{S}^{B}$ and $\frac{2 b-3}{2 b^{2}-4}<k \leq k_{1}$, then the supplier encroaches under information sharing but not under non-information sharing.

(iii) If $F>\Gamma_{S}^{B}$ and $\frac{1}{4}<k \leq \frac{1}{2}$, then the supplier never encroaches.

Recall Theorem 4.4, in which the retailer may prefer to share demand information voluntarily depending on the supplier's encroachment decision. Proposition 5.1 suggests that although the decision sequence has changed, the main results obtained from our basic model still hold. It is worth noting that the quality cost coefficient threshold when the supplier encroaches and the entry cost threshold are different from those in the basic model.

Sequential (II): In this scenario, the retailer carries out the quantity before the supplier's quantity decisions are considered. This is considered because such a setting inevitably leads to leaking of private demand information, in which the former model turns out to be a signaling game [13,24]. To simplify the case, a binary demand 


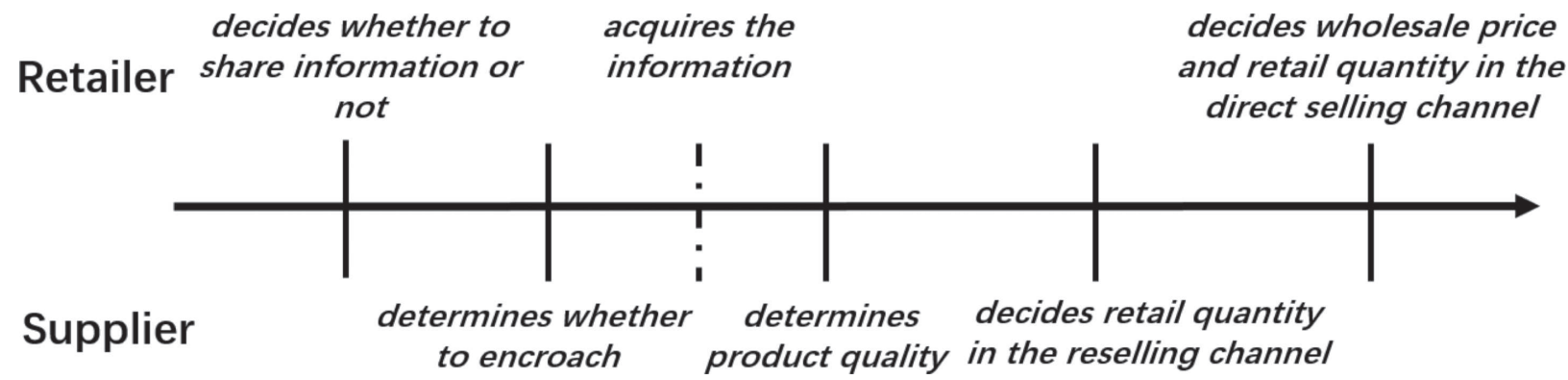

Figure 3. Game timing of sequential (II).

distribution is employed-either $\theta_{H}=2 d$ for high demand or $\theta_{L}=0$ for low demand-and the distribution cannot change our main results. The corresponding probability for the demand is described as $\operatorname{Pr}\left(\theta_{H}\right)=\operatorname{Pr}\left(\theta_{L}\right)=\frac{1}{2}$.

As demonstrated in the extant literature [13,24], the pooling equilibrium fails to include the intuition criterion in the model setting. However, the pure state of a separating equilibrium includes a natural case in which the retailer perfectly discloses the observed demand signal without distortion, along with a case of quantity distortion, in which the selling quantity must be distorted if the observed demand is high in the retail channel. Based on [13], the current study only focuses on the natural case, since the payoff in the naturally separating equilibrium is more lucrative than in the one with distortion. Moreover, the retailer will be overwhelmingly willing to ex-ante share demand information in the case of distortion if she always does so in a naturally separating equilibrium. All solutions are presented in the Appendix, and the retailer's information sharing decision in equilibrium is discussed in the following proposition.

Proposition 5.2. When the retailer decides on the quantity before the supplier, there exist thresholds $k_{2}, k_{3}$, and $\tilde{b}$ such that the retailer shares demand information with the supplier when $k_{2}<k<k_{3}$, or $b<\tilde{b}$ and $k>k_{3}$.

Proposition 5.2 indicates that the main results in the basic model still hold, in which the product quality has a huge impact on the retailer's decision to share demand information with the supplier. Moreover, the extant literature on signal games reveals that high-type demand signals may mimic the low type to prevent the supplier's encroachment $[13,24]$. Compared with the selling quantity distortion, we show that it may be beneficial for the retailer to voluntarily share demand information with the supplier to induce engagement in the marketplace.

\subsection{Price competition}

We study Cournot competition between a retailer and a supplier who decides to encroach in Section 3. In this section, we investigate Bertrand competition between the supplier and retailer; however, the decision sequence is consistent with the basic model. Following [11], if the retailer's decision is the retail price, the demand function is given by

$$
q_{i}=a+\theta+m-(1+b) p_{i}+b p_{j} \text { for } i \neq j, i=r, s
$$

Notably, if the supplier does not encroach, the equilibrium outcomes under the retailer's quantity decision are the same as those under the retailer's price decision. In the following, we only derive the equilibrium outcomes under price competition. However, we assume $k>\frac{18 b^{3}+45 b^{2}+40 b+12}{2(1+b)\left(9 b^{2}+16 b+8\right)}$ to ensure the optimal solve positively.

Non-information sharing. We first characterize the supplier's encroachment decision under the condition of non-information sharing. The ex-ante profit gap between encroachment and non-encroachment is given by $\Gamma_{N}^{p}=\frac{k \sigma(2+3 b)\left[\sigma\left(6+11 b+6 b^{2}-12 a(1+b)^{2}\right)\right]}{36 b^{3}(k-1)+8(4 k-3)+16 b(6 k-5)+10 b^{2}(10 k-9)}$, where superscript "P" represents the price competition case. 
Information sharing. We then present the supplier's decision to encroach under the information sharing condition. The following function shows the ex-ante profit gap between encroachment and non-encroachment $\Gamma_{S}^{p}=\frac{k^{2}\left(a^{2}+\sigma^{2}\right)\left(16+56 b+65 b^{2}+27 b^{3}\right)}{(4 k-1)\left[18 b^{3}(k-1)+4(4 k-3)+8 b(6 k-5)+5 b^{2}(10 k-9)\right]}$.

Based on the information above, we present the firms' equilibrium decisions, as stated in the following proposition.

Proposition 5.3. In equilibrium, the retailer prefers to share demand information when one of the following conditions hold:

(i) If $F \leq \Gamma_{N}^{P}$ and $\frac{18 b^{3}+45 b^{2}+40 b+12}{2(1+b)\left(9 b^{2}+16 b+8\right)}<k<k_{4}$, the supplier always encroaches.

(ii) If $\Gamma_{N}^{P}<F \leq \Gamma_{S}^{P}$ and $\frac{18 b^{3}+45 b^{2}+40 b+12}{2(1+b)\left(9 b^{2}+16 b+8\right)}<k \leq k_{5}$, the supplier encroaches under the information sharing condition but not under the non-information sharing condition.

(iii) If $F>\Gamma_{S}^{P}$ and $\frac{1}{4}<k<\frac{1}{2}$, the supplier never encroaches.

Proposition 5.3 indicates that the retailer's decision to share information depends on the supplier's decision to encroach; that is, the retailer will share information with the supplier voluntarily under certain conditions. In other words, under both Cournot and Bertrand competition, the retailer prefers to share demand information no matter what encroachment decision the supplier makes, because she can benefit from adjusting product quality level. That is, when the retailer faces the supplier's encroachment, although the competition between the direct selling channel and the reselling channel is intense, she still prefers to voluntarily share demand information with the supplier. This result is in sharp contrast with that of $[13,14]$.

\subsection{Supplier encroachment timing}

In Section 3, we assume that the supplier makes an encroachment decision after the retailer decides whether to share demand information. Here, we consider a case in which the supplier decides whether to encroach first, and then the retailer decides whether to share demand information [see, e.g., 13]. The other settings are in line with our basic model. We summarize the main results in the following proposition.

Proposition 5.4. In equilibrium,

(i) if $\frac{1}{4}<k \leq \frac{1}{2}$, the supplier encroaches when $F \leq \Gamma_{S}$, and then the retailer shares the information;

(ii) if $\frac{1}{2}<k \leq \frac{6-b}{4+6 b}$, the supplier encroaches when $F \leq \Gamma_{S N}$ and then the retailer shares information under encroachment; in contrast, when the retailer does not share information under non-encroachment, $\Gamma_{S N}=\frac{k\left(-2 a^{2}(-2+b)^{2} k+(-3+2 b)(-1+4 k) \sigma^{2}\right)}{2(-1+4 k)\left(3-2 b+2\left(-2+b^{2}\right) k\right)}$;

(iii) if $k>\frac{6-b}{4+6 b}$, the supplier encroaches when $F \leq \Gamma_{N}$, and then the retailer does not share demand information.

In our basic analysis, we show that the supplier's encroachment decision is based on the retailer's decision to share information. However, Proposition 5.4 states that the retailer's decision to share information is contingent on the supplier's encroachment. A significant result is obtained, that is, different from that of [13]: we show that the retailer will share demand information under certain conditions. It is worth noting that the supplier prefers to encroach if the quality cost coefficient is medium. That is, although the timing of supplier encroachment is changed, our main results still hold.

\subsection{Supplier quality decision timing}

Section 3 shows that product quality level is determined after the retailer acquires market demand information, which reveals the importance of quality level in information sharing. One concern is that if the decision is made before the retailer acquires the information, the impact of quality decisions on the retailer's decision to share information during supplier encroachment remains unclear. In fact, this consideration is reasonable as some products with a single selling season must be designed and produced in advance of the demand information revelation [17]. To address this issue, we first fix the product quality under non-encroachment and encroachment and then consider the retailer's information sharing strategies. The primary results are as follows. 
Proposition 5.5. In equilibrium,

(i) when $F \leq \Gamma_{N}$, the retailer never shares demand information with the supplier;

(ii) when $F>\Gamma_{S}$, there is no demand information shared invariably;

(iii) when $\Gamma_{N}<F<\Gamma_{S}$, the retailer may share information with the supplier if and only if $\tilde{k_{1}}<k<\tilde{k_{2}}$.

As demonstrated in Proposition 5.5 (i) and (ii), when decisions on product quality level are made prior to acquiring demand information, the retailer is always encouraged not to share demand information with the supplier. Intuitively, when the quality level is decided before demand information acquisition, demand information fails to function in terms of quality level, which worsens only the bullwhip effect. In other words, if the entry cost is low or high, it is detrimental for the retailer to share demand information, which differs from Theorem 4.4.

However, if the entry cost is intermediate in (iii), the retailer may prefer to share private demand information with the supplier. However, the supplier could decide whether to encroach based on an information sharing policy, which is consistent with Proposition 4.3. In effect, both firms could benefit from information sharing and encroachment when the quality coefficient $k$ is moderate. This is because product quality may have a more positive influence on market demand if it is shared, and the potential value may outweigh the loss from higher wholesale prices and encroachment. This discussion of supplier quality decision timing further demonstrates the importance and necessity of product quality in this study.

\section{Conclusion}

In practice, more and more suppliers are establishing a direct selling channel to compete with the retailers' channel to increase profits. We developed a standard information sharing model under a classic encroachment scenario in which a supplier provides a product with a certain quality level to a retailer, and then chooses whether to establish a direct selling channel in a supply chain. The retailer first decides whether to share demand information; then, the supplier determines whether to encroach (if he encroaches, he incurs a fixed entry cost), after which the retailer acquires the information. Our study concentrates on investigating the interaction between information sharing, product quality decision, and the supplier's encroachment decision.

Our main results are summarized as follows. First, in a basic model analysis, surprisingly, the retailer may voluntarily share demand information with her supplier. Concretely, if the supplier does not encroach, information sharing becomes beneficial to the retailer when the quality cost coefficient is low. Moreover, if the supplier encroaches, the retailer prefers to share demand information with her supplier when the quality cost coefficient is moderate. Interestingly, we find that the supplier prefers to encroach if the retailer shares information when the entry cost is moderate. Note that the threshold of the quality cost coefficient depends on channel substitutability. That is, the retailer shares information under certain conditions, regardless of whether the supplier encroaches. These results are in sharp contrast with those of [13], indicating that the retailer decides not to share information with the supplier because of the double marginalization effect of information sharing. Second, we also show that the supplier prefers to establish a direct selling channel when the quality cost coefficient is high; that is, the threshold of entry cost increases with the quality cost coefficient. Third, we find that the retailer has more incentive to share demand information under supplier encroachment conditions than under non-encroachment conditions. This is because the supplier can adjust the product quality to enhance market demand. Therefore, the retailer is more willing to share information in response to the supplier's effort. Moreover, we include some extensions, such as the sequential quantity decision and pricing competition, to confirm the robustness of our obtained results.

Our analysis is based on some assumptions that can provide future research directions. First, our study builds a one-to-one supply chain. It is therefore worth investigating a case in which horizontal competition between the retailers determines whether to share demand information and between suppliers who determine whether to encroach. Second, recently, since adopting an omni-channel in a supply chain is popular in operations management, future works could study the interaction between information sharing, product quality decisions, and supplier's encroachment decision in an omni-channel supply chain. Third, we assume that the supplier 
produces one product with a certain quality level. However, it is worth examining a case in which the supplier produces quality differentiated products. We leave these issues for future work.

\section{Appendix A. Proof of Lemma 4.1}

If the supplier does not encroach, and the retailer does not share the information, then the retailer's payoff is given by $\max \pi_{r}=\left(a+\theta+m-q_{r}-w\right) q_{r}$. Solving the first-order condition to obtain $q_{r}^{N N}=\frac{a+\theta+m-w}{2}$. The supplier's payoff is given by $\max \pi_{s}=E\left[\left(a+\theta+m-q_{r}^{N N}-w\right)\right] w-\frac{k m^{2}}{2}$. Solving the first-order condition to obtain $w^{N N}=\frac{a+m}{2}$ and $m^{N N}=\frac{a}{4 k-1}$. Based on the above, the supplier's and the retailer's optimal payoff are respectively given by

$$
\pi_{s}^{N N}=\frac{k a^{2}}{8 k-2}, \pi_{r}^{N N}=\frac{\sigma^{2}(1-8 k)+4 k^{2}\left(a^{2}+4 \sigma^{2}\right)}{4(1-4 k)^{2}} .
$$

If the supplier encroaches, and the retailer does not share information, then the supplier's payoff is given by the equation (4.1), and the retailer's payoff is given by the equation (4.2). Solving the first-order condition to obtain $q_{r}^{N E}=\frac{a(2 b-4)+(2 b-4) m+\left(b^{2}-4\right) \theta-4 w}{2\left(4-b^{2}\right)}$ and $q_{s}^{N E}=\frac{a(b-2)+(b-2) m-b w}{4-b^{2}}$. Finally, we obtain $w^{N E}=-\frac{\left[8+(b-4) b^{2}\right](a+m)}{6 b^{2}-16}$ and $m^{N E}=-\frac{a(b-2)(b-6)}{12-16 k+b(-8+b+6 b k)}$. Therefore, the supplier's and the retailer's optimal payoff are respectively given by

$$
\begin{aligned}
& \pi_{s}^{N E}=-\frac{a^{2}(-2+b) k(-6+b)}{24-32 k+2 b(-8+b+6 b k)}, \\
& \pi_{r}^{N E}=\frac{[8 a(-1+b) k]^{2}+(12-16 k+b(-8+b+6 b k))^{2} \sigma^{2}}{4(12-16 k+b(-8+b+6 b k))^{2}} .
\end{aligned}
$$

Based on the above, we can obtain the supplier's encroachment threshold when the information is withheld as follows:

$$
\pi_{s}^{N E}-\pi_{s}^{N N}=\Gamma_{N}=-\frac{[16+b(5 b-16)] k^{2}\left(a^{2}+\sigma^{2}\right)}{(4 k-1)[12-16 k+b(-8+b+6 b k)]} .
$$

That is, if the fixed entry cost $F \leq \Gamma_{N}$, the supplier encroaches; otherwise, he does not.

\section{Appendix B. Proof of Lemma 4.2}

If the supplier does not encroach, and the retailer shares information. The supplier's and the retailer's optimal payoff are respectively given by

$$
\pi_{s}^{S N}=\frac{k\left(a^{2}+\sigma^{2}\right)}{8 k-2}, \pi_{r}^{S N}=\frac{k^{2}\left(a^{2}+\sigma^{2}\right)}{(1-4 k)^{2}} .
$$

If the supplier encroaches, and the retailer shares information. The supplier's and the retailer's optimal payoff are respectively given by

$$
\begin{aligned}
\pi_{s}^{S E} & =-\frac{(-6+b)(-2+b) k\left(a^{2}+\sigma^{2}\right)}{24-32 k+2 b(-8+b+6 b k)} \\
\pi_{r}^{S E} & =\frac{16(-1+b)^{2} k^{2}\left(a^{2}+\sigma^{2}\right)}{(12-16 k+b(-8+b+6 b k))^{2}} .
\end{aligned}
$$

Therefore, we can obtain the supplier's encroachment threshold when the information is shared as follows:

$$
\pi_{s}^{S E}-\pi_{s}^{S N}=\Gamma_{S}=-\frac{[16+b(5 b-16)] k^{2}\left(a^{2}+\sigma^{2}\right)}{(4 k-1)[12-16 k+b(-8+b+6 b k)]} .
$$

That is, if the fixed entry cost $F \leq \Gamma_{S}$, the supplier encroaches; otherwise, he does not. 


\section{Appendix C. Proof of Proposition 4.3}

This proof can be derived from Lemma 4.1-4.2. However, it is worth noting that $k_{0}$ is the unique solution of equation $\pi_{r}^{S E}=\pi_{r}^{N N}$.

\section{Appendix D. Proof of Theorem 4.4}

First, we examine the retailer's equilibrium information decision when the supplier encroaches. According to Eqs. (4.5) and (4.6), if the retailer shares information, then we have

$$
\begin{aligned}
& \frac{16(b-1)^{2} k^{2}\left(a^{2}+\sigma^{2}\right)}{[12-16 k+b(-8+b+6 b k)]^{2}}-\frac{[8 a(b-1) k]^{2}+[12-16 k+b(-8+b+6 b k)]^{2} \sigma^{2}}{4[12-16 k+b(-8+b+6 b k)]^{2}} \\
& =-\frac{(-2+b)(-6+b+4 k+6 b k)(12-24 k+b(-8+b+8 k+6 b k)) \sigma^{2}}{4[12-16 k+b(-8+b+6 b k)]^{2}}>0,
\end{aligned}
$$

because we assume $k>\frac{8 b-b^{2}-12}{6 b^{2}-16}$ to ensure the equilibrium solves positively. Therefore the retaile $\mathrm{r}$ prefers to share information with the supplier if and only if $\frac{8 b-b^{2}-12}{6 b^{2}-16}<k \leq \frac{6-b}{4+6 b}$ when the supplier encroaches.

Similarly, we then examine the retailer's equilibrium information decision when the supplier does not encroach. By a similar manner, if the retailer shares information, then we have

$$
\frac{k^{2}\left(a^{2}+\sigma^{2}\right)}{(1-4 k)^{2}}-\frac{4 k^{2}\left(a^{2}+4 \sigma^{2}\right)+(1-8 k) \sigma^{2}}{4(1-4 k)^{2}}=-(-1+2 k)(-1+6 k) \sigma^{2}>0,
$$

because we assume $k>\frac{1}{4}$ to ensure the equilibrium outcomes solve positively. Therefore the retailer prefers to share information with the supplier if and only if $\frac{1}{4}<k \leq \frac{1}{2}$ when the supplier does not encroach.

\section{Appendix E. Proof of Corollary 4.5}

Combining Lemma 4.1-4.2 and Theorem 4.4, the proof can be obtained easily.

\section{Appendix F. Proof of Proposition 4.6}

Combining Lemma 4.1-4.2 and Theorem 4.4, the proof can be obtained easily.

\section{Appendix G. Proof of Proposition 5.1}

The proof procedure is similar to Theorem 4.4, thus we omit it here. It is worth noting that $k_{1}$ is the unique solution of equation $\pi_{r}^{S E}=\pi_{r}^{N N}$. However, we present the supplier's payoff and the retailer's payoff as follows.

If the supplier encroaches and he is informed, then we have

$$
\begin{aligned}
& \pi_{s}^{*}=\frac{(-3+2 b) k\left(a^{2}+\sigma^{2}\right)}{6-8 k+4 b(-1+b k)}, \\
& \pi_{r}^{*}=\frac{(-1+b)^{2} k^{2}\left(a^{2}+\sigma^{2}\right)}{\left(3-2 b+2\left(-2+b^{2}\right) k\right)^{2}} .
\end{aligned}
$$

If the supplier encroaches and he is not informed, then we have that

$$
\begin{aligned}
\pi_{s}^{*} & =\frac{a^{2}(-3+2 b) k}{6-8 k+4 b(-1+b k)}, \\
\pi_{r}^{*} & =\frac{(2 a(-1+b) k)^{2}+\left(3-2 b+2\left(-2+b^{2}\right) k\right)^{2} \sigma^{2}}{6-8 k+4 b(-1+b k)} .
\end{aligned}
$$




\section{Appendix H. Proof of Proposition 5.2}

With no encroachment. If there is no information sharing, both firms' expected profits in equilibrium are $\pi_{R}^{N N}=\frac{\left(d^{2}(4 k-1)^{2}+2 a^{2} k^{2}+2 a d k(4 k-1)\right)}{\left(2(4 k-1)^{2}\right)}$ and $\pi_{S}^{N N}=\frac{(a k(a+2 d))}{(8 k-2)}$, respectively. If information sharing policy is taken, their profits in equilibrium are $\pi_{R}^{S N}=\frac{\left(a^{2}+2 a d+2 d^{2}\right) k^{2}}{(4 k-1)^{2}}$ and $\pi_{S}^{S N}=\frac{\left(a^{2}+2 a d+2 d^{2}\right) k}{(8 k-2)}$, respectively.

With encroachment. Under supplier's encroachment and retailer's information sharing, we conld show their expected payoffs: $\pi_{R}^{S E}=\frac{4\left(-2-2 b+b^{2}+b^{3}\right)^{2}\left(a^{2}+2 a d+2 d^{2}\right) k^{2}}{\left(12+b(16-32 k)+b^{2}(3-14 k)-16 k+2 b^{4} k+b^{3}(4 k-2)\right)^{2}}$ and $\pi_{S}^{S E}=$

$\frac{\left(-12-16 b-3 b^{2}+2 b^{3}\right)\left(a^{2}+2 a d+2 d^{2}\right) k}{24+b(32-64 k)+b^{2}(6-28 k)-32 k+4 b^{4} k+b^{3}(8 k-4)}$. A signal game begins when the retailer gets rejected to share her private demand information with the supplier, where the supplier would adjust his direct selling quantity $q_{S}$ by observing retail quantity $q_{R}$. Based on [24], our model setting could not make the pooling equilibrium hold, and therefore, the pure-strategic separating equilibrium is only considered. The supplier's brlief is

$$
j\left(q_{R}\right)=\left\{\begin{array}{l}
H \text { if } q_{R} \geq \tilde{q}_{R}(w), \\
L \text { otherwise, }
\end{array}\right.
$$

which means that the supplier believes that the random demand $\theta_{i}(\forall i \in=\{H, L\})$ is high $\left(\theta_{H}\right)$ if retailer's selling quantity $q_{R}>\tilde{q}_{R}(w)$. Otherwise, it is $\theta_{L}$. We set $\theta_{j_{q_{R}}(w)}$ as market size that the supplier's belief holds after the retailer's quantity $q_{R}$. Given the belief, the supplier decides selling quantity $q_{S}$ by solving $\pi_{S}\left(q_{S}\right)=\left[\left(a+\theta_{j\left(q_{R}\right)}-q_{S}-b q_{R}\right) q_{S}+w q_{R}\right]$, leading to the optimal responsive function $q_{S}\left(q_{R}\right)=\frac{a+\theta+q-b q_{R}}{2}$. Analogous to $[13,24]$, we define

$$
G_{i j}\left(q_{R}\right)=\left[a+\theta_{i}-q_{R}-b\left(\frac{a+\theta+q-b q_{R}}{2}\right)-w\right] q_{R}, \quad \forall i, j \in\{H, L\},
$$

as the retailer's profit when the ture random demand is $\theta_{i}$, and the supplier's belief to the demand is $\theta_{j}$.

As deduced in this paper, $G_{i j}\left(q_{R}\right)$ is concave in $q_{R}$, and $G_{i i}\left(q_{R}\right)$ could be reach maximum at the point of $q_{R}^{i}=\frac{\left(a+\theta_{i}+q\right)(2+b)-2 w(1+b)}{4(1+b)}, \forall i \in\{H, L\}$. Defind $\bar{q}_{R}(w)=\frac{(a+q)(2-b)+4 d-2 w}{2\left(2-b^{2}\right)}-\frac{\sqrt{b d[(a+q)(2-b)+(4-b) d-2 w]}}{2-b^{2}}$ and $\bar{w}=\frac{(2-b)(a+q+2 d)}{2}$. It could be proved that $G_{H L}\left(\bar{q}_{R}(w)\right) \leq G_{H H}\left(q_{R}^{H}(w)\right)$ if and only if $\mathrm{w}>\bar{w}$. Hence, a unique separating equilibrium holds, where the retailer's quantity accords with $q_{R}\left(w, \theta_{H}\right)=q_{R}^{H}(w)$, and $q_{R}\left(w, \theta_{L}\right)=$ $\check{q}_{R}(w)=\min \left\{q_{R}^{L}(w), \bar{q}_{R}(w)\right\}$, and the supplier's direct selling quantity could be $q_{S}\left(q_{R}\left(w, \theta_{i}\right)\right)=\frac{a+q+\theta_{i}-b q_{R}\left(w, \theta_{i}\right)}{2}$ for $\forall i \in\{H, L\}$. Dependent on the retailer's quantity decision, the supplier solve the following payoff function.

$$
\pi_{S}(w)=E_{\theta}\left[\left(a+\theta-q_{S}\left(q_{R}(w, \theta)\right)-b q_{R}(w, \theta)\right) q_{S}+w q_{R}(w, \theta)-\frac{k q^{2}}{2}\right] .
$$

Note that the signal game begins when the scenario of non-information sharing and encroachment holds in equilibrium. And the optimal wholesale price and each firms' selling quantity are shown respectively,

(i) $w^{N E}=\frac{(-4 b(1+b) d+(-8+(-4+b) b(2+b))(a+q))}{\left(2(1+b)\left(-8+b^{2}\right)\right)}, q_{R}^{N E}\left(\theta_{i}\right)=\frac{\left((2+b)\left(a+q+\theta_{i}\right)-8 w(1+b)\right)}{4(1+b)}$ and $q_{S}^{N E}\left(\theta_{i}\right)=$ $\underline{\left(2 a\left(-8-14 b-5 b^{2}+b^{3}\right) k-2(1+b) d\left(4+2 b+b^{2}(-1+k)+b^{3} k\right)+\left(12+b(16-32 k)+b^{2}(3-14 k)-16 k+2 b^{4} k+b^{3}(-2+4 k)\right) \theta_{i}\right)}$ $\left(24+b(32-64 k)+b^{2}(6-28 k)-32 k+4 b^{4} k+b^{3}(-4+8 k)\right)$

(ii) $w^{N E}=\min \{\tilde{w}, \bar{w}\}, q_{R}^{N E}\left(\theta_{L}\right)=\bar{q}_{R}\left(w^{N E}\right), q_{R}^{N E}\left(\theta_{H}\right)=\frac{\left(a+\theta_{H}+q\right)(2+b)-2(1+b) w^{N E}}{4(1+b)}$ and $q_{S}^{N E}\left(\theta_{i}\right)=$ $\frac{a+q+\theta_{i}-b q_{R}^{N E}\left(\theta_{i}\right)}{2}$, where $\tilde{w}=\min \left\{\max \left\{\frac{a+2 d+q-b q_{R}\left(w, \theta_{H}\right)+\left(a-b \bar{q}_{R}(w)\right)^{2}+w\left(q_{R}\left(w, \theta_{H}\right)+\bar{q}_{R}(w)\right)}{4}\right\}\right\}$.

The proof is the same as $[13,24]$, and thus we does not include in this paper. Case (i) denotes natural separating equilibrium, while case (ii) points to the separating equilibrium with quantity distortion. In this section, we only consider case (i), the natural saparating equilibrium. The reason is that the retailer will have much stronger motivation to distort her selling quantity if she commits to sharing the information with the supplier in natural separating equilibrium. 
According to the aforementioned analysis, the supplier's optimal encroachment decision is obtained. Define $\Omega_{N}=-\frac{[16+b(5 b-16)] k^{2} a^{2}}{(4 k-1)[12-16 k+b(6 b k+b-8)]}$. If no demand information is shared, the supplier does choose to encroach if and only if $\mathrm{F} \leq \Omega_{N}$ but he never encroches if $\mathrm{F}>\Omega_{N}$.

The retailer's expected payoffs would be shown respectively,

$$
\left\{\begin{array}{l}
\pi_{R}^{N}= \begin{cases}\frac{4 a^{2} k^{2}+2(1-4 k)^{2} d^{2}}{4(1-4 k)^{2}} & F>\Omega_{N}, \\
\frac{\left(2 a\left(b^{2}-2\right) k+d\left(2 b^{2} k-2+b(2 k-1)\right)\right)\left(4 a(1+b)^{2}\left(b^{2}-2\right) k+d\left(20+b(34-76 k)+b^{2}(14-48 k)-32 k+2 b^{5} k+b^{3}(6 k-3)+2 b^{4}(6 k-1)\right)\right)}{2\left(12+b(16-32 k)+b^{2}(3-14 k)-16 k+2 b^{4} k+b^{3}(4 k-2)\right)^{2}} & F \leq \Omega_{N},\end{cases} \\
\pi_{R}^{S}= \begin{cases}\frac{k^{2}\left(a^{2}+2 d^{2}\right)}{(1-4 k)^{2}} & F>\Omega_{S}, \\
\frac{4\left(-2-2 b+b^{2}+b^{3}\right)^{2}\left(a^{2}+2 a d+2 d^{2}\right) k^{2}}{\left(12+b(16-32 k)+b^{2}(3-14 k)-16 k+2 b^{4} k+b^{3}(-2+4 k)\right)^{2}} & F \leq \Omega_{S},\end{cases}
\end{array}\right.
$$

With no encroachment, the retailer's incentive to share demand information is consistent with our previous conclusion. Please see Theorem 4.4 (i). With encroachment, the retailer shares her priveta information with the supplier when $\frac{-12+b(-16+b(-3+2 b))}{2(1+b)^{2}\left(-8+b^{2}\right)}<k<\frac{-8+b\left(-8+b+2 b^{2}\right.}{2(1+b)^{2}\left(-4+b^{2}\right)}$, or $\mathrm{k}>\frac{-8+b\left(-8+b+2 b^{2}\right)}{2(1+b)^{2}\left(-4+b^{2}\right)}$ and $\mathrm{a}<\frac{d\left(-(2+b)^{2}(-10+b(-12+b(-1+2 b)))+2(1+b)(2+b)(-16+b(-32+b(-14+b(4+3 b)))) k-4(1+b)^{2}\left(-16+b\left(-16+b\left(-6+b\left(-2+b+b^{2}\right)\right)\right)\right) k^{2}\right)}{2(2+b)\left(b^{2}-2\right) k\left(8+8 b-b^{2}-2 b^{3}+2(1+b)^{2}\left(b^{2}-4\right) k\right)}$

\section{Appendix I. Proof of Proposition 5.3}

The proof procedure is similar to Theorem 4.4, thus we omit it here. However, it is worth noting that $k_{2}$ is the unique solution of equation $\pi_{r}^{S E}=\pi_{r}^{N N}$.

If the supplier encroaches and he is informed, then we have

$$
\begin{aligned}
& \pi_{s}^{*}=\frac{4(1+b)^{2}\left(2+b^{2}\right)^{2} k^{2}\left(a^{2}+\sigma^{2}\right)}{\left(-12+4 b-b^{2}+b^{3}+2(1+b)\left(8+b^{2}\right) k\right)^{2}}, \\
& \pi_{r}^{*}=-\frac{(-2+b)\left(6+b+b^{2}\right) k\left(a^{2}+\sigma^{2}\right)}{2\left(-12+4 b-b^{2}+b^{3}+2(1+b)\left(8+b^{2}\right) k\right)} .
\end{aligned}
$$

If the supplier encroaches and he is not informed, then we have

$$
\begin{aligned}
& \pi_{s}^{*}=-\frac{a(-2+b) k\left(a\left(6+b+b^{2}\right)\right)}{2\left(-12+4 b-b^{2}+b^{3}+2(1+b)\left(8+b^{2}\right) k\right)}, \\
& \pi_{r}^{*}=\frac{\left(4 a(1+b)\left(2+b^{2}\right) k\right)^{2}+\left(-12+b(4+(-1+b) b)+2(1+b)\left(8+b^{2}\right) k\right)^{2} \sigma^{2}}{4\left(-12+4 b-b^{2}+b^{3}+2(1+b)\left(8+b^{2}\right) k\right)^{2}} .
\end{aligned}
$$

\section{Appendix J. Proof of Proposition 5.4}

The proof procedure is similar to Theorem 4.4, thus we omit it here. However, we should obtain the condition of $\pi_{s}^{S E}>\pi_{s}^{N N}$.

\section{Appendix K. Proof of Proposition 5.5}

When the quality level q is supposed to be decided before demand observed, we can conclude

$$
\begin{aligned}
q^{N} & =\frac{a}{4 k-1}, \\
q^{E} & =\frac{a(3-2 b)}{2 b+2\left(2-b^{2}\right) k-3}
\end{aligned}
$$


where the letters of "N" and "E" denote no encroachment and encroachment. Under this quality level, we begin to exmine the incentive of information sharing. With no encroachment $\left(F<\Gamma_{S}\right)$, the retailer's expected functions are

$$
\begin{aligned}
& \pi_{R}^{N N}=\frac{4 a^{2} k^{2}+(1-4 k)^{2} \sigma^{2}}{4(1-4 k)^{2}}, \\
& \pi_{R}^{S E}=\frac{16 a^{2} k^{2}+(1-4 k)^{2} \sigma^{2}}{16(1-4 k)^{2}} .
\end{aligned}
$$

Apparently, $\pi^{N S}<\pi^{N N}$. And with supplier's encroachment $\left(F \leq \Gamma_{N}\right)$, the retailer's expected functions are

$$
\begin{aligned}
& \pi_{R}^{N E}=\frac{4 a^{2}(1-b)^{2} k^{2}+\sigma^{2}\left(3-2 b-4 k+2 k b^{2}\right)}{4\left(3-2 b-4 k+2 k b^{2}\right)^{2}}, \\
& \pi_{R}^{S E}=\frac{4(1-b)^{2}\left[4 a^{2} k^{2}\left(2-b^{2}\right)^{2}+\sigma^{2}\left(3-2 b-4 k+2 k b^{2}\right)\right]}{\left(8-3 b^{2}\right)^{2}\left(3-2 b-4 k+2 k b^{2}\right)^{2}} .
\end{aligned}
$$

where a inequility of $\pi_{R}^{S E}<\pi_{R}^{N E}$ always holds. When the retailer's information sharing policy depends on the supplier's encroachment, we find that $\pi^{S E}>\pi^{N N}$ if and only if $\tilde{k}_{1}<k<\tilde{k}_{2}$, where $\tilde{k}_{1}=\frac{3-2 b}{4-2 b^{2}}$ and $\tilde{k}_{2}=\operatorname{Root}\left[432 \sigma^{2}-288 b \sigma^{2}-76 b^{2} \sigma^{2}+896 b^{3} \sigma^{2}-175 b^{4} \sigma^{2}-108 b^{5} \sigma^{2}+36 b^{6} \sigma^{2}+\left(-4608 \sigma^{2}+2304 b \sigma^{2}+8768 b^{2} \sigma^{2}-\right.\right.$ $\left.8192 b^{3} \sigma^{2}+160 b^{4} \sigma^{2}+1520 b^{5} \sigma^{2}-180 b^{6} \sigma^{2}-72 b^{7} \sigma^{2}\right) \# 1+\left(2048 a^{2}-2560 a^{2} b-704 a^{2} b^{2}+1792 a^{2} b^{3}-252 a^{2} b^{4}-\right.$ $304 a^{2} b^{5}+80 a^{2} b^{6}+16896 \sigma^{2}-4096 b \sigma^{2}-35072 b^{2} \sigma^{2}+22016 b^{3} \sigma^{2}+8480 b^{4} \sigma^{2}-6848 b^{5} \sigma^{2}-688 b^{6} \sigma^{2}+576 b^{7} \sigma^{2}+$ $\left.36 b^{8} \sigma^{2}\right) \# 1^{2}+\left(-4096 a^{2}+7680 a^{2} b^{2}-1024 a^{2} b^{3}-4704 a^{2} b^{4}+1088 a^{2} b^{5}+944 a^{2} b^{6}-288 a^{2} b^{7}-24576 \sigma^{2}-4096 b \sigma^{2}+\right.$ $\left.56320 b^{2} \sigma^{2}-12288 b^{3} \sigma^{2}-30720 b^{4} \sigma^{2}+9472 b^{5} \sigma^{2}+4928 b^{6} \sigma^{2}-1152 b^{7} \sigma^{2}-288 b^{8} \sigma^{2}\right) \# 1^{3}+\left(8192 a^{2} b-7168 a^{2} b^{2}-\right.$ $8192 a^{2} b^{3}+7744 a^{2} b^{4}+2048 a^{2} b^{5}-2368 a^{2} b^{6}+144 a^{2} b^{8}+12288 \sigma^{2}+8192 b \sigma^{2}-28672 b^{2} \sigma^{2}-8192 b^{3} \sigma^{2}+21760 b^{4} \sigma^{2}+$ $\left.\left.2048 b^{5} \sigma^{2}-6400 b^{6} \sigma^{2}+576 b^{8} \sigma^{2}\right) \# 1^{4} \&, 2\right]$.

Acknowledgements. We thank the Editor-in-Chief (Prof. Ridha Mahjoub), and the anonymous referees for their constructive and insightful comments, which help us significantly improve the quality of our paper. This work was supported by the National Natural Science Foundation of China (grant 72072041), the Chinese National Funding of Social Science (19BGL094), and the Guangzhou Data and Law Research Center.

\section{REFERENCES}

[1] A. Arya, B. Mittendorf and D. Sappington, The bright side of supplier encroachment. Mark. Sci. 26 (2007) $651-659$.

[2] R.D. Banker, I. Khosla and K.K. Sinha, Quality and competition. Manag. Sci. 44 (1998) 1179-1192.

[3] C.B. Bucklin, P.A. Thomas-Graham and E.A. Webster, Channel conflict: When is it dangerous?. McKinsey Quarterly 3 (1997) 36-43.

[4] P. Chen, B. Li and H. Huang, Decision policies on players? different risk combination under supplier encroachment. RAIROOper. Res. 54 (2020) 1057-1075.

[5] W.-y.K. Chiang, D. Chhajed and J.D. Hess, Direct Marketing, Indirect Profits: A Strategic Analysis of Dual-Channel SupplyChain Design. Manag. Sci. 49 (2003) 1-20.

[6] H. Guan, H. Gurnani, X. Geng and Y. Luo, Strategic inventory and supplier encroachment. Manuf. Serv. Oper. Manag. 21 (2018) 536-555.

[7] X. Guan, L. Baoshan and Y. Chen, Inducing supply chain transparency through supplier encroachment. Prod. Oper. Manag. 29 (2019) 725-749.

[8] X. Guan, Y. Wang, Z. Yi and Y. Chen, Inducing Consumer Online Reviews Via Disclosure. Prod. Oper. Manag. 29 (2020) 1956-1971.

[9] L. Guo, The benef its of downstream information acquisition. Mark. Sci. 28 (2008) 457-471.

[10] A. Ha, X. Long and J. Nasiry, Quality in supply chain encroachment. Manuf. Serv. Oper. Manag. 18 (2016) $280-298$.

[11] A. Ha, Q. Tian and S. Tong, Information sharing in competing supply chains with production cost reduction. Manuf. Serv. Oper. Manag. 19 (2017) 1-17.

[12] K. Heron, Try the red: Napa learns to sell (2010).

[13] S. Huang, X. Guan and Y.J. Chen, Retailer Information Sharing with Supplier Encroachment. Prod. Oper. Manag. 27 (2018) 1133-1147. 
[14] S. Huang, S. Chen and X. Guan, Retailer information sharing under endogenous channel structure with investment spillovers. Comput. Ind. Eng. (2020) 106346.

[15] B. Huo, M.Z.U. Haq and M. Gu, The impact of information sharing on supply chain learning and flexibility performance. Int. J. Prod. Res. 0 (2020) 1-24.

[16] G. Iyer, C. Narasimhan and R. Niraj, Information and inventory in distribution channels. Manag. Sci. 53 (2007) $1551-1561$.

[17] K. Jerath, S.-H. Kim and R. Swinney, Product Quality in a Distribution Channel with Inventory Risk. Mark. Sci. 36 (2017) $747-761$.

[18] B. Jiang and B. Yang, Quality and pricing decisions in a market with consumer information sharing. Manag. Sci. 65 (2018) $272-285$.

[19] H. Lee, K. So and C. Tang, The value of information sharing in a two-level supply chain. Manag. Sci. 46 (2000) 626-643.

[20] C.H. Lee, B.-D. Rhee and T.C.E. Cheng, Quality uncertainty and quality-compensation contract for supply chain coordination. Eur. J. Oper. Res. 228 (2013) 582-591.

[21] H. Lei, J. Wang, L. Shao and H. Yang, Ex post demand information sharing between differentiated suppliers and a common retailer. Int. J. Prod. Res. 58 (2020) 703-728.

[22] L. Li and H. Zhang, Confidentiality and information sharing in supply chain coordination. Manag. Sci. 54 (2008) $1467-1481$.

[23] X. Li and X. Qi, On pricing and quality decisions with risk aversion. Omega (2019) 102118.

[24] Z. Li, S. Gilbert and G. Lai, Supplier encroachment under ssymmetric information. Manag. Sci. 60 (2014) $449-462$.

[25] Z. Li, S.M. Gilbert and G. Lai, Supplier Encroachment as an Enhancement or a Hindrance to Nonlinear Pricing. Prod. Oper. Manag. 24 (2015) 89-109.

[26] X. Lin, Y.-W. Zhou and R. Hou, Impact of a ?Buy-online-and-pickup-in-store? Channel on Price and Quality Decisions in a Supply Chain. Eur. J. Oper. Res. 294 (2021) 922-935.

[27] Y. Liu and Z. Zhang, The benefits of personalized pricing in a channel. Mark. Sci. 25 (2006) 97-105.

[28] Z. Liu, D.J. Zhang and F. Zhang, Information Sharing on Retail Platforms. Manuf. Serv. Oper. Manag. 23 (2021) 606-619.

[29] J. Ma and Y. Hong, Research on manufacturer encroachment with advertising and design of incentive advertising: A gametheoretic approach. RAIRO-Oper. Res. 55 (2021) S1261-S1286.

[30] N. Matsubayashi, Price and quality competition: The effect of differentiation and vertical integration. Eur. J. Oper. Res. 180 (2007) 907-921.

[31] V.K. Mishra, K. Natarajan, D. Padmanabhan, C.P. Teo and X. Li, On theoretical and empirical aspects of marginal distribution choice models. Manag. Sci. 60 (2014) 1511-1531.

[32] R. Niraj and C. Narasimhan, Vertical information sharing in distribution channels. SSRN Electron. J. (2004)

[33] S. Ray, H. Chen, M. Bergen and D. Levy, Asymmetric wholesale pricing: Theory and evidence. Texas A\&SM: Mark. (Topic) 25 (2005).

[34] W. Shang, A.Y. Ha and S. Tong, Information sharing in a supply chain with a common retailer. Manag. Sci. 62 (2016) $245-263$.

[35] N. Singh and X. Vives, Price and quantity competition in a differentiated duopoly. RAND J. Econ. 15 (1984) 546-554.

[36] X. Sun, W. Tang, J. Chen, S. Li and J. Zhang, Manufacturer encroachment with production cost reduction under asymmetric information. Transp. Res. Part E: Logist. Transp. Rev. 128 (2019) 191-211.

[37] X. Sun, W. Tang, J. Zhang and J. Chen, The impact of quantity-based cost decline on supplier encroachment. Transp. Res. Part E: Logist. Transp. Rev. 147 (2021) 102245.

[38] J. Tannenbaum, Franchisees resist poaching via software, kiosks, Internet. Wall Str. J. (1995).

[39] S. Wang, Q. Hu and W. Liu, Price and quality-based competition and channel structure with consumer loyalty. Eur. J. Oper. Res. 262 (2017) 563-574.

[40] T.-Y. Wang, Y.-L. Li, H.-T. Yang, K.-S. Chin and Z.-Q. Wang, Information sharing strategies in a hybrid-format online retailing supply chain. Int. J. Prod. Res. 59 (2021) 3133-3151.

[41] Y. Wei and P. Huang, Information sharing in the hybrid-format supply chain. SSRN Electron. J. (2019).

[42] X. Xu, Optimal Price and Product Quality Decisions in a Distribution Channel. Manag. Sci. 55 (2009) $1347-1352$.

[43] M. Xue, J. Zhang and G. Zhu, Quantity decision timing with spillover effect and asymmetric demand information. Transp. Res. Part E: Logist. Transp. Rev. 142 (2020) 102048.

[44] M. Xue and J. Zhang, Supply chain encroachment with quality decision and different power structures. RAIRO-Oper. Res. 54 (2020) 693-718.

[45] H. Zhang, Vertical Information exchange in a supply chain with duopoly retailers. Prod. Oper. Manag. 11 (2002) 531-546.

[46] S. Zhang and J. Zhang, Agency selling or reselling: E-tailer information sharing with supplier offline entry. Eur. J. Oper. Res. 280 (2020) 134-151. 
[47] J. Zhang, S. Li, S. Zhang and R. Dai, Manufacturer encroachment with quality decision under asymmetric demand information. Eur. J. Oper. Res. 273 (2019) 217-236.

[48] S. Zhang, J. Zhang and G. Zhu, Retail service investing: An anti-encroachment strategy in a retailer-led supply chain. Omega 84 (2019) 212-231.

\section{Subscribe to Open (S2O) A fair and sustainable open access model}

This journal is currently published in open access under a Subscribe-to-Open model (S2O). S2O is a transformative model that aims to move subscription journals to open access. Open access is the free, immediate, online availability of research articles combined with the rights to use these articles fully in the digital environment. We are thankful to our subscribers and sponsors for making it possible to publish this journal in open access, free of charge for authors.

\section{Please help to maintain this journal in open access!}

Check that your library subscribes to the journal, or make a personal donation to the S2O programme, by contacting subscribers@edpsciences.org

More information, including a list of sponsors and a financial transparency report, available at: https://www. edpsciences.org/en/maths-s2o-programme 